\title{
Влияние природы наполнителя на свойства композита «поливиниловый спирт : полисахарид»
}

\author{
(C) 2021 Студеникина Л.Н., Корчагин В.И., Иушин В.О., Мельников А.А. \\ Воронежский государственный университет инженерных технологий, Воронеж
}

Поступила в редакцию 9.10.2020 г.

DOI: $10.17308 /$ sorpchrom.2021.21/3226

При получении и применении высоконаполненных композитов на основе поливинилового спирта (ПВС) возникает вопрос оценки влияния особенностей структурообразования при формовании на свойства материала. Целью данной работы является исследование влияния природы наполнителя и наличия пластификатора при получении высоконаполненных композитов «ПВС-1799 : полисахарид (ПС)» на основные эксплуатационные показатели (прочность, водопоглощение, биодеструкция). В качестве наполнителей использовали микроцеллюлозу древесную (МЦД), крахмал кукурузный (КК), клетчатку кофейного зерна (ККЗ), часть образцов была модифицирована пластификатором (П) - глицерином (в количестве 5 об.\%). Содержание наполнителя составляло от 50 до 80 об.\%. Композиты в виде пластин получали жидкофазным совмещением 5\%-го раствора ПВС и порошка ПС с последующим обезвоживанием в вакуум-сушильном шкафу. Установлено, что максимальную прочность после вымачивания имеет образец ПВС:КК:П, его напряжение при разрыве снизилось лишь в 5 раз, а удлинение при этом возросло в 17 раз (для сравнения - у образцов ПВС:МЦд:П и ПВС:ККЗ:П напряжение при разрыве снизилось в 43 и 14 раз, а удлинение возросло в 5и 4 раза соответственно). Показано, что водопоглощение ПВС выбранной марки достигает 800\% по массе в первые 5 минут вымачивания, при содержании в ПВС 80 об.\% наполнителей различной природы водопоглощение снижается в 3-15 раз. Установлено, что наибольший коэффициент диффузии - у образца, наполненного ККЗ, наименьший у крахмалонаполненного ПВС, что можно объяснить различной плотностью упаковки молекулярных и надмолекулярных структур. Предварительные испытания компостируемости исследуемых композитов показали, что для их полной биодеградации потребуется не менее 6 месяцев воздействия деструкторов. Для композита ПВС:МЦД при содержании наполнителя 50, 65 и 80 об.\% потеря прочности через 6 месяцев компостирования составила 89, 87 и 95\%, а индекс деструкции $-9,8,19$ соответственно. Предварительно установлено, что скорость биодеградации при компостировании композитов ПВС:ПС увеличивается в ряду ПВС:КК $<$ ПВС:ККЗ $<$ ПВС:МЦД.

Ключевые слова: поливиниловый спирт, полисахариды, микроцеллюлоза, крахмал, клетчатка, композит, биодеградируемые материалы.

\section{Введение}

Среди разрабатываемых материалов, способных к биодеградации, рядом преимуществ (дешевизна, хорошие технологические и эксплуатационные свойства, возможность регулирования сроков деструкции и др.) обладают композиты на основе синтетических термопластов, имеющих в составе полярные группы. Максимальное наполнение синтетических матриц природными полимерами (в частности, полисахаридами: крахмалом, целлюлозой и пр.) направлено на получение композиций с минимально возможным содержанием искусственных невозобновляемых компонентов, удешевление конечного продукта, а также на придание композитам новых уникальных свойств [1].

Перспективность применения композитов на основе поливинилового спирта (ПВС) и полисахаридов (ПС) в качестве 
биодеградируемых материалов отмечают зарубежные исследователи [2,3]. Однако при получении и применении таких материалов возникает ряд вопросов, требующих изучения. Во-первых, при жидкофазном совмещении полимерной матрицы и наполнителя возникает необходимость подбора оптимальной технологии гомогенизации, обезвоживания и формования продукта, при этом особенности структурообразования будут существенно влиять на свойства композита (прочность, водопоглощение, биодеградация и др.). Во-вторых, биодеградация ПВС и композитов на его основе зависит от нескольких факторов: степени полимеризации, содержания ацетатных групп, стереорегулярности и др., что требует комплексной оценки влияния технологических аспектов получения на эффективность деструкции композита в различных условиях.

Известно, что модификация ПВС наполнителями и добавками изменяет структуру макромолекул, в частности стереорегулярность и связанную с ней кристалличность [4], уменьшение числа разветвлений в молекуле поливинилового спирта значительно увеличивает водостойкость и температуру размягчения и снижает растворимость [5], а «сшивка» ПВС при технологической обработке может приводить к снижению его растворимости и диффузии ферментов в материал [6]. В работе [7] также отмечено, что сшитые гелеобразующие полимеры сохраняют способность набухать, но теряют способность растворяться в растворителях. При подборе технологических добавок к биодеградируемым композитам следует учитывать, что природа модификатора может существенно влиять на эффективность биодеструкции [8].

Процессы биодеструкции ПВС исследовались в работах $[9,10]$, полученные результаты подчеркивают сложный характер деградации данного полимера в окружающей среде. Термин «биодеградация» подразумевает поэтапную трансформацию полимера в углекислый газ, воду, неорганические соединения, включающиеся в естественный круговорот веществ. В работе [11] отмечено, что неверно считать биодеградируемыми все полимеры, характеризующиеся высокой сорбцией воды (к которым в частности относится и ПВС). Количественные данные о процессе биохимических превращений полимерных материалов, вызываемых биодеструкторами и обеспечивающих им возможность ассимиляции материала в качестве источника питательных веществ, весьма ограничены [12]. Исследования влияния стереорегулярности ПВС на его биодеградируемость в присутствии бактерии-деструктора Pseudomonas sp. (по показателю снижения общего органического углерода (TOC) в культуре PVA) показали, что изотактический ПВС (iPVA), имеющий ряд длинных мезопоследовательностей, восприимчив к биодеградации, а ПВС с высокой синдиотактичностью (s-PVA) - нет [10].

Целью данной работы явилось получение высоконаполненных композитов «ПВС:ПС» и исследование влияния природы наполнителя и наличия пластификатора на их основные эксплуатационные показатели (прочность, водопоглощение, биодеструкция).

\section{Экспериментальная часть}

В качестве объектов исследования были выбраны композиты на основе ПВС марки 1799, наполненного полисахаридами различной природы: микроцеллюлозой древесной (МЦД) марки «Filtracell», крахмалом кукурузным (КК), клетчаткой кофейного зерна (ККЗ). Часть образцов была модифицирована пластификатором (П) - глицерином (в количестве 5 об.\%). Композиты в виде пластин получали жидкофазным совмещением 5\%-го раствора ПВС и порошка ПС с последующим обезвоживанием в вакуум-сушильном шкафу. Содержание наполнителя составляло от 
50 до 80 об.\%.

Макроструктуру композитов

определяли с помощью цифрового микроскопа Levenhuk-D670T с программным обеспечением Levenhuk Toup View. Прочностные показатели оценивались по ГОСТ 11262-17 (с помощью разрывной машины PM-50 с программным обеспечением «StretchTest»), водопоглощение - по ГОСТ 46502014, компостирование проводилось согласно ГОСТ Р 54530-2011.

\section{Обсуждение результатов}

Формирование структуры полимерной композиции определяется, прежде всего, свойствами матрицы и наполнителя, характером распределения последнего и природой их взаимодействия на границе раздела фаз, которая может быть изменена введением пластификаторов. Форма и размер частиц наполнителя играет важнейшую роль при структурообразовании композита. Выбранные для исследования наполнители представляют собой: МЦД - волокнистые частицы размером 10-200 мкм, КК - мелкодисперсные (5-35 мкм) зернистые частицы, ККЗ - крупнодисперсные (50-500 мкм) зернистые частицы, гигроскопичность выбранных наполнителей возрастает в ряду ККЗ $<$ КК $<$ МЦД.

ПВС - пленкообразующий кристалли- зующийся полимер, однако, при получении пленок ПВС методом полива из водного раствора, особенно в присутствии крупнодисперсных наполнителей и пластификаторов, он остается преимущественно аморфным. Пластификация композитов позволяет значительно снизить дефектообразование при формовании материала, что наглядно отражено на рис. 1. Следует отметить поведение композита, наполненного МЦД, для которого дефекты при отсутствии пластфикатора значительно менее выражены, чем у композитов с КК и ККЗ, что можно объяснить низкой скоростью влагоотдачи наполнителя (способствующей «пролонгированной» пластификации ПВС водой), а также эффектом армирующего наполнителя.

Макроструктура композитов ПВС:МЦД (20 : 80 об.\%) показана на рис. 2. Структура гетерогенна, наполнитель распределен однородно в виде «сетки», при большем увеличении видны поры, что является важным фактором для проникновения ферментов в объем композита при биодеградации. Для ПВС, наполненного КК, отмечена плотная однородная структура и отсутствие пор, что еще более выражено при введении пластификатора. Образцы с ККЗ имеют неоднородную зернистую структуру и значительную шероховатость поверхности.

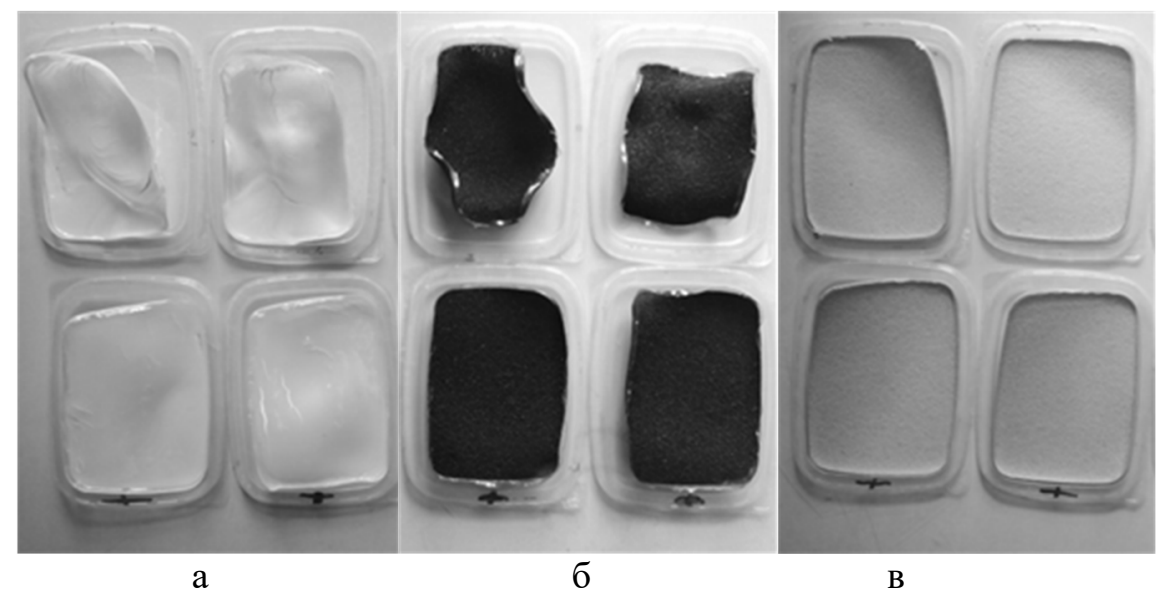

Рис. 1. Внешний вид образцов ПВС:ПС, 20:80 об.\% (верхний ряд) и ПВС:ПС:П, 20:75:5 об.\% (нижний ряд), при использовании в качестве ПС: а - КК, б - ККЗ, в - МЦД

Fig. 1. Appearance of PVA samples: PS, 20:80 vol\% (top row) and PVA:PS:P, 20:75:5 vol\% (bottom row), when used as a PS: a - CS, b-CBC, c-WMCC 


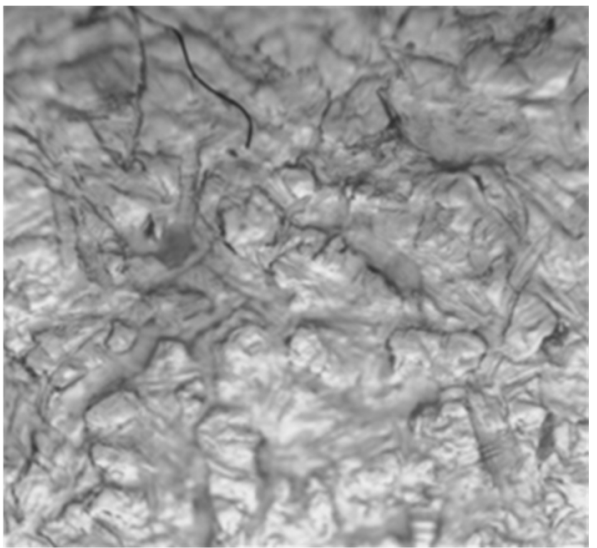

a

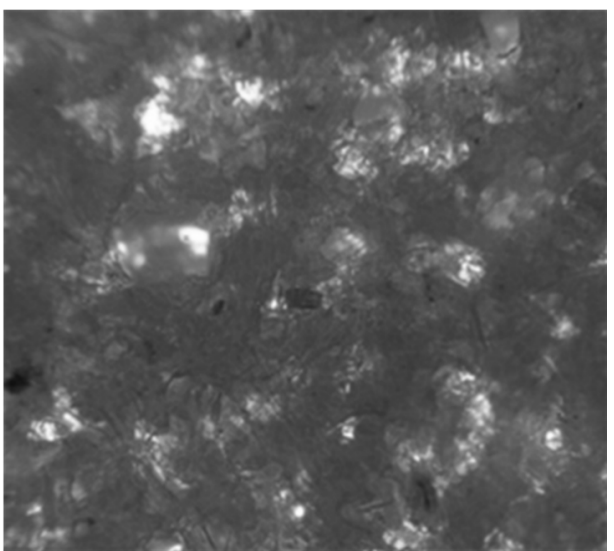

6

Рис. 2. Макроструктура композитов ПВС:МЦД (20:80 об.\%) при увеличении:

$$
\mathrm{a}-\mathrm{x} 40,6-\mathrm{x} 100
$$

Fig. 2. Macrostructure of PVA:WMCC composites (20:80 vol\%) with magnification:

$$
a-x 40, b-x 100
$$

При получении высоконаполненных композитов одним из наиболее важных эксплуатационных показателей является прочность, а при использовании водорастворимых полимерных матриц целесообразна оценка их физикомеханических показателей после контакта с водой, которая также позволит определить степень влияния природы наполнителя и пластификатора на проникновение воды в объем композита и происходящие при этом процессы. Прочностные показатели исследуемых материалов отражены в таблице 1 .

Установлен различный характер влияния пластификатора на прочность композитов, отличающихся природой наполнителя. Введение глицерина в композит ПВС:МЦ способствует снижению прочности (в 1.7 раза) и повышению удлинения (в 2.2 раза). Для композита ПВС:ККЗ снизилась и прочность (в 2.2 раза) и относительное удлинение (в 1.3 раза). Образец ПВС:КК имеет слишком высокую хрупкость, которая не позволила определить прочностные показатели, однако при введении пластификатора композит становится эластичным и имеет максимальное среди прочих композитов удлинение при разрыве. После вымачивания все образцы показали снижение прочности и повышение удлинения при разрыве, причем для ПВС с МЦД разница показателей у образцов с пластификатором и без незначительна (прочность снизилась в 43 и 41 раз, удлинение повысилось в 5 и 6 раз соответственно), у ПВС с ККЗ без пластификатора прочность снизилась в

Таблица 1. Показатели прочности композитов «ПВС:ПС» $(20: 80$ об.\%) и «ПВС:ПС:П» (20:75:5 об.\%)

Table 1. Strength indicators of the composites "PVA:PS" (20:80 vol\%) And "PVA:PS:P" (20:75:5 vol\%).

\begin{tabular}{|l|c|c|c|c|c|c|}
\hline \multirow{2}{*}{ Показатель } & \multicolumn{6}{|c|}{ Значение в зависимости от природы наполнителя: } \\
\cline { 2 - 7 } & МЦД & МЦД:П & КК & КК:П & ККЗ & ККЗ:П \\
\hline Прочность при разрыве, МПа & 5.35 & 3.20 & $-* *$ & 2.10 & 0.84 & 0.37 \\
\hline Относительное удлинение, \% & 3 & 6,7 & $-* *$ & 9.8 & 6,2 & 4.7 \\
\hline Прочность при разрыве*, МПа & 0.13 & 0,08 & 0.09 & 0.43 & 0.02 & 0.03 \\
\hline Относительное удлинение*, \% & 17.5 & 33.5 & 21.6 & 166.3 & 25 & 18.4 \\
\hline
\end{tabular}

*через 1 час вымачивания, **показатели отсутствуют из-за хрупкости образца, не позволяющей выполнить испытания

*after 1 hour of soaking, ** indicators are absent due to the brittleness of the sample, which did not allow testing 


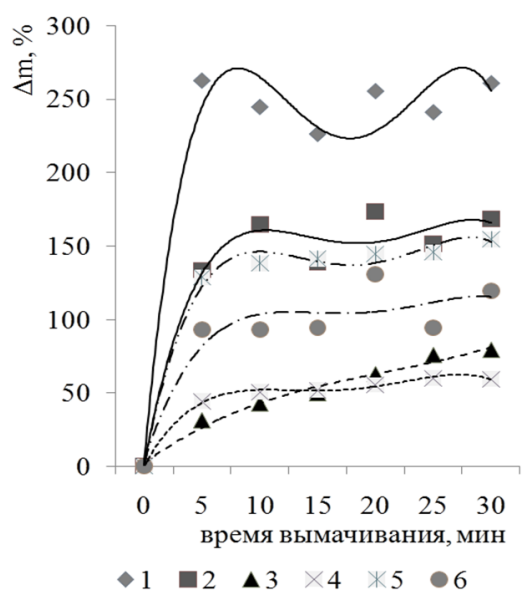

Рис. 3. Динамика водопоглощения композитов ПВС:ПС (20:80 об.\%) и ПВС:ПС:П (20:75:5 об.\%):

1 -ПВС:МЦД, 2 - ПВС:МЦД:П, 3 - ПВС:КК, 4 - ПВС:КК:П, 5 - ПВС:ККЗ, 6 - ПВС:ККЗ:П

Fig. 3. Dynamics of water absorption of composites PVA:PS (20:80 vol\%) and PVA:PS:P (20:75:5 vol\%): 1 - PVA:WMCC, 2 - PVA:WMCC: P, 3 - PVA:CS, 4 -

PVA:CS: P, 5 - PVA:CBC, 6 - PVA:CBC:P

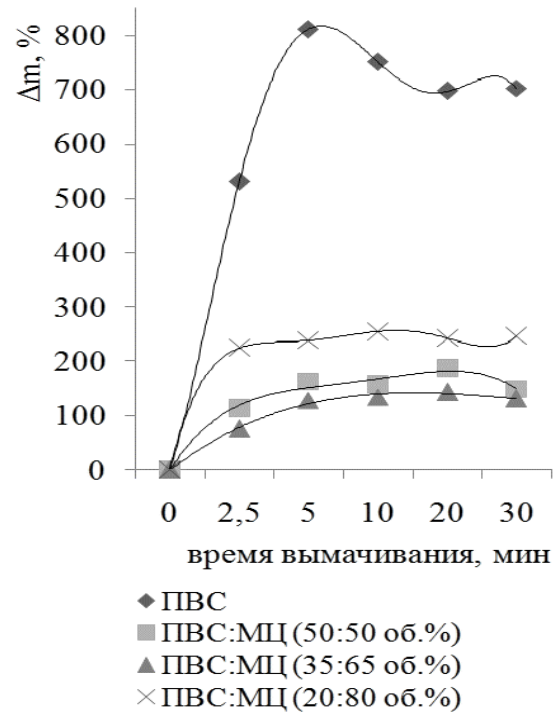

Рис. 4. Динамика водопоглощения композитов ПВС:МЦД

Fig. 4. Dynamics of water absorption of composites PVA:WMCC
42 раза, а в его присутствии - лишь в 14 раз. Максимальные показатели после вымачивания имеет образец ПВС:КК:П, его прочность снизилась лишь в 5 ра3, а удлинение при этом возросло в 17 раз.

В исследовании [13] отмечено, что кинетика набухания гелеобразующих полимеров определяется в первую очередь не диффузией воды в гель, а более медленной релаксацией полимерных цепей. Введение наполнителя изменяет релаксационные процессы в период набухания ПВС, замедляя диффузию воды. Водопоглощение ПВС выбранной марки достигает $800 \%$ по массе в первые 5 минут вымачивания, при содержании в композите 80 об.\% наполнителей различной природы водопоглощение снижается в 3-15 раз (рис. 3). В случае с МЦД отмечен эффект повышения водопоглощения при увеличении содержания наполнителя в композите (рис. 4). На основании полученных данных были рассчитаны коэффициенты диффузии воды в исследуемые композиты по методике, описанной в ГОСТ 12020-72 (таблица 2). Установлено, что наибольший коэффициент диффузии - у образца, наполненного ККЗ, наименьший - у крахмалонаполненного ПВС, что можно объяснить различной плотностью упаковки молекулярных и надмолекулярных структур. В присутст-

Таблица 2. Коэффициент диффузии D ( $\left.\mathrm{cm}^{2} / \mathrm{c}\right)$ воды для композитов «ПВС:ПС» (20:80 об.\%) и «ПВС:ПС:П» $(20: 75: 5$ об.\%)

Table 2. Diffusion coefficient D $\left(\mathrm{cm}^{2} / \mathrm{s}\right)$ of water for composites "PVA:PS" (20:80 vol\%) and "PVA:PS:P" (20:75:5 vol\%)

\begin{tabular}{|c|c|c|c|c|c|c|}
\hline & \multicolumn{6}{|c|}{ Состав композита: } \\
\cline { 2 - 7 } & ПВС:МЦД & ПВС:МЦД:П & ПВС:КК & ПВС:КК:П & ПВС:ККЗ & ПВС:ККЗ:П \\
\hline $\begin{array}{c}\mathrm{D}, \\
\mathrm{cm}^{2} / \mathrm{c}\end{array}$ & $1.48 \cdot 10^{-6}$ & $1.19 \cdot 10^{-6}$ & $5.93 \cdot 10^{-7}$ & $4.23 \cdot 10^{-7}$ & $4.63 \cdot 10^{-6}$ & $4.12 \cdot 10^{-6}$ \\
\hline
\end{tabular}


вии пластификатора скорость проникновения воды в объем композита незначительно снижается для всех исследуемых образцов.

Показатели потери прочности композитных материалов позволяют удобно и достоверно оценить скорость деструктивных процессов под воздействием различных факторов, при этом используется термин «индекс деструкции» (отношение фактической убыли какого-либо характерного показателя полимера (вязкости, прочности и т.д.) к максимально возможной). Чем больше индекс деструкции, тем более подвержен полимер к данному внешнему воздействию. Если образцы композитов с одинаковой полимерной матрицей различаются индексами деструкции, это свидетельствует о различных механизмах разложения, протекающих внутри материала [14].

Предварительные испытания компостируемости исследуемых композитов показали, что для их полной биодеградации потребуется не менее 6 месяцев воздействия деструкторов. Для композита ПВС:МЦД при содержании наполнителя 50, 65 и 80об.\% потеря прочности через 6 месяцев компостирования составила 89,87 и $95 \%$, а индекс деструкции - 9.8, 19 соот-

\section{Список литературы}

1. Корчагин В.И., Студеникина Л.Н. // Пластические массы. 2019. № 9-10. С.52-55.

2. Qiu K., Netravail A.N. Biodegradable Polymers. Vol. 1: Advancement in biodegradation study and applications. Nova Science Publishers Inc. NewYork. 2015. pp. 325-379.

3. Guo B., Zha D., Li B., Yin P. et al. // Materials. 2018. Vol. 11. No 4. pp. 640-643.

4. Лазарева Т.Г., Ильющенко И.А., Алимов И.Ф. // Высокомолекулярные соединения. Серия А. 1994. Т. 36. № 9. С. 1481-1485.

5. Роговин 3.А. Основы химии и технологии химических волокон. М. Химия. 1974,. T. $1.518 \mathrm{c}$. ветственно. Предварительно установлено, что скорость биодеградации при компостировании композитов ПВС:ПС увеличивается в ряду ПВС:КК $<$ ПВС:ККЗ $<$ ПВС:МЦД.

\section{Заключение}

Полученные данные позволяют прогнозировать поведение композитов состава «ПВС:ПС» в процессе их изготовления, эксплуатации и утилизации. Введение гигроскопичного волокнистого наполнителя с размером частиц в пределах 200 мкм (древесная микроцеллюлоза) благодаря армирующему эффекту улучшает формуемость и прочность композита, а также способствует увеличению степени водопоглощения и скорости биодеградации. Зернистые наполнители различной дисперсности в отсутствии пластификатора приводят к дефектообразованию при получении композита, мелкодисперсные частицы способствуют более плотной упаковке молекулярных и надмолекулярных структур, что замедляет диффузию воды в композит. Введение пластификатора в композит на основе ПВС и крахмала значительно повышает прочностные показатели влагонасыщенного материала.

6. Моргачева А.А. Дисс. канд. хим.наук. М. 2019. $16 \mathrm{c}$.

7. Ферапонтов Н.Б., Гагарин А.Н., Токмачёв М.Г. // Сорбичионные $u$ хроматографические процессы. 2016. Т. 16. № 3. C . $368-376$

8. Студеникина Л.Н. Дисс. канд. техн. наук. Воронеж. 2012. 159 p.

9. Chiellini E., Corti A., D'Antone S. et al. // Progress in Polymer Science. 2003. Vol. 28. pp. 963-1014. doi.org/10.1016/S0079-6700(02) 00149-1

10. Fukae Ryohei, Nakata Koji, Takeo Masahiro, Yamamoto Tohei et al. // Sen'igakkaishi Fiber. 2000. Vol. 56. No 5. pp. 254-258

11.Штильман М.И. // Journal of Siberian 
Federal University. Biology. 2015. Vol. 8. No 2. pp. 113-130.

12. Горение, деструкция и стабилизация полимеров / под ред. Заикова Г.Е. СанктПетербург. Науч. основы и технологии. 2008. $421 \mathrm{c}$.

13. Иванов В.А., Карпюк Е.А.,
Шелковникова Л.А., Гавлина О.Т. // Сорб- ционные и хроматографические прочессы. 2016. T. 16. № 5. C.569-581

14.Корчагин В.И., Суркова А.М., Студеникина Л.Н., Протасов А.В. // Известия высших учебных заведений. Серия: Химия и химическая технология. 2019. Т. 62. № 2. С. $101-107$

\title{
Influence of the filler nature on the properties of the composite "polyvinyl alcohol: polysaccharide"
}

\author{
(C) 2021 Studenikina L.N., Korchagin V. I., Iushin V. O., Melnikov A.A. \\ Voronezh state University of Engineering Technologies, Voronezh, Russian Federation
}

\begin{abstract}
The question about assessing the influence of the features of structure formation during moulding on the properties of the material arises during production and application of highly filled composites based on polyvinyl alcohol (PVA). The purpose of this study was the investigation of the effect of the nature of the filler and the presence of a plasticizer during the production of highly filled composites "PVA-1799: polysaccharide (PS)" on the main performance indicators (strength, water absorption, biodegradation). Wood microcrystalline cellulose (WMCC), corn starch (CS), and coffee bean cellulose (CBC) were used as fillers; some of the samples were modified with a plasticizer $(\mathrm{P})$ - glycerol (in an amount of $5 \mathrm{vol} \%$ ). The filler content was from 50 to 80 vol\%. Composites in the form of plates were obtained by liquid-phase combination of a 5\% PVA solution and PS powder, followed by dehydration in a vacuum laboratory oven. It was found that the PVA:CS:P sample had the maximum strength after soaking, its breaking strain decreased by only 5 times, while the elongation increased by 17 times (for comparison, for the PVA:WMCC:P and PVA:CBC:P the breaking strain decreased by 43 and 14 times, and the elongation increased by 5 and 4 times, respectively). It has been shown that the water absorption of PVA of the selected brand reaches $800 \%$ by weight in the first 5 minutes of soaking; when the PVA contains $80 \mathrm{vol} \%$ of fillers of various natures, the water absorption decreases by 3-15 times. The highest diffusion coefficient was revealed for the sample filled with CBC, the lowest was for starch-filled PVA, which can be explained by the different packing density of molecular and supramolecular structures. Preliminary compostability tests of the studied composites showed that their complete biodegradation would require at least 6 months of exposure to destructors. For the PVA:WMCC composite with a filler content of 50,65 , and $80 \mathrm{vol} \%$, the loss of strength after 6 months of composting was 89,87 , and $95 \%$, and the destruction index was $9,8,19$, respectively. It was previously established that the rate of biodegradation during composting of PVA:PS composites increases in the series of PVA:CS $<$ PVA:CBC $<$ PVA:WMCC.
\end{abstract}

Keywords: polyvinyl alcohol, polysaccharides, microcellulose, starch, cellulose, composite, biodegradable materials.

\section{References}

1. Korchagin V.I., Studenikina L.N., Plastic masses, 2019, No 9-10, pp. 52-55

2. Qiu K., Netravail A.N. Biodegradable Polymers. Volume 1: Advancement in biodegradation study and applications. Nova Science Publishers Inc., NewYork, 2015, pp. 325-379.

3. Guo B., Zha D., Li B., Yin P. et al., Materials, 2018, Vol. 11, No 4, pp.640-643

4. Lazareva T. G., Ilyushenko I. A., Alimov I., High-molecular compounds. Series A, 1994, Vol. 36, No 9, pp. 1481-1485.
5. Rogovin Z.A. Fundamentals of chemistry and technology of chemical fibers, M., Chemistry, 1974, Vol.1, $518 \mathrm{p}$.

6. Morgacheva A.A. Diss. cand. of chem. Nauk, M., 2019, 16 p.

7. Ferapontov N.B., Gagarin A.N., Tokmachev M.G., Sorbtsionnye $i$ khromatograficheskiye protsessy, 2016, Vol. 16, No 3, pp. 368-376.

8. Studenikina L.N., Diss. cand. tech. nauk, Voronezh, 2012, $159 \mathrm{p}$.

9. Chiellini E., Corti A., D'Antone S., Solaro R., Progress in Polymer Science, 2003, Vol. 28, pp. 963-1014. doi.org/10.1016/S0079-6700(02) $00149-1$ 
10.Fukae Ryohei, Nakata Koji, Takeo Masahiro, Yamamoto Tohei et al., Sen'igakkaishi Fiber, 2000, Vol. 56, No 5, pp. 254-258.

11.Shtilman M.I., Journal of Siberian Federal University. Biology, 2015, Vol. 8, No 2, pp. 113130.

12.Gorenje, destruction and stabilization of polymers. / Ed. Zaikova G.E. SPb, Scientific foundations and technologies, 2008, $421 \mathrm{p}$.

Студеникина Любовь Николаевна - к.т.н., доцент кафедры промышленной экологии, оборудования химических и нефтехимических производств, Воронежский государственный университет инженерных технологий, Воронеж

Корчагин Владимир Иванович заведующий кафедрой промышленной экологии, д.т.н., оборудования химических и нефтехимических производств, ВГУИТ, Воронеж

Иушин Василий Олегович - студент кафедры технологии органических соединений, переработки полимеров и техносферной безопасности, ВГУИТ, Воронеж

Мельников Александр Александрович студент кафедры промышленной экологии, оборудования химических и нефтехимических производств, ВГУИТ, Воронеж
13.Ivanov V.A., Karpyuk E.A., Shelkovnikova

L.A., Gavlina O.T., Sorbtsionnye $i$ khromatograficheskiye protsessy, 2016, Vol. 16, No 5, pp. 569-581.

14.Korchagin V.I., Surkova M.A., Studenikina L.N., Protasov A.V., Izvestiya Vysshikh Uchebnykh Zavedenii, Seriya Khimiya $i$ Khimicheskaya Tekhnologiya, 2019, Vol. 62, No 2, pp. 101-107.

Studenikina Lubov N. - PhD, docent, industrial ecology, chemical and petrochemical production equipment department, Voronezh state university of engineering technologies, Voronezh, Russia, lubovchurkina@yandex.ru

Korcagin Vladimir I. - the professor, head of the department of industrial ecology, chemical and petrochemical production equipment department, Voronezh state university of engineering technologies, Voronezh

Iushin Vasiliy O. - student, of organic compounds technology, polymer processing and technosphere safety department, Voronezh state university of engineering technologies, Voronezh

Melnikov Alexandr A. - student, industrial ecology, chemical and petrochemical production equipment department, Voronezh state university of engineering technologies, Voronezh 